

\title{
From Idea to Reality: Extensive and Executable Modeling Language for Mobile Learning Games
}

Iza Marfisi-Schottman, Pierre-Yves Gicquel, Aous Karoui, Sébastien George

\section{To cite this version:}

Iza Marfisi-Schottman, Pierre-Yves Gicquel, Aous Karoui, Sébastien George. From Idea to Reality: Extensive and Executable Modeling Language for Mobile Learning Games. European Conference on Technology Enhanced Learning,, Sep 2016, Lyon, France. pp.428 - 433, 10.1007/978-3-319-451534_38. hal-01383208

\section{HAL Id: hal-01383208 https://hal.science/hal-01383208}

Submitted on 19 Oct 2016

HAL is a multi-disciplinary open access archive for the deposit and dissemination of scientific research documents, whether they are published or not. The documents may come from teaching and research institutions in France or abroad, or from public or private research centers.
L'archive ouverte pluridisciplinaire HAL, est destinée au dépôt et à la diffusion de documents scientifiques de niveau recherche, publiés ou non, émanant des établissements d'enseignement et de recherche français ou étrangers, des laboratoires publics ou privés. 


\title{
From Idea to Reality: Extensive and Executable Modeling Language for Mobile Learning Games
}

\author{
Iza Marfisi-Schottman, Pierre-Yves Gicquel, Aous Karoui, and Sébastien George \\ LUNAM Université, Université du Maine, EA 4023, LIUM, 72085 Le Mans, France \\ \{iza.marfisi, pierre-yves.gicquel, aous.karoui, sebas- \\ tien.georges \} : @univ-lemans.fr
}

\begin{abstract}
Mobile Learning Games (MLGs) show great potential for education, especially in fields that deal with outdoor learning activities such as archaeology or botany. However, the number of MLGs currently used remains insignificant. This is partly due to the fact that the current authoring tools are based on modeling languages that only allow creating very specific and rigid types of MLGs. In this paper, we therefore propose an extensive modeling language for MLGs. This model was designed, with the help of botanical experts, in order to cover the variety of MLG types they would like for their field trips. This modeling language uses highlevel concepts, such as game activities and points of interest on a map that can therefore be used by teachers in any domain. Finally, we discuss how scenarios, described with this language, can be automatically transformed into executable web applications.
\end{abstract}

Keywords. Mobile Learning Game, Game-Based Learning, Serious Games, Modeling Language, Scenario

\section{Introduction}

Mobile Learning Games (MLGs) have proven their efficiency in various domains of education. Gaius' Day, for example, is used by history teachers, during archaeological outings Egnathia in Italie [1]. Frequency1550 is used to teach high-school students about history in medieval Amsterdam [2] and Skattjakt is another historical MLG used during the visit of a Swedish castle [3].

However, even though MLGs show great potential, very few are actually used by teachers. Yet, there are several authoring tools that enable teachers to create their own MLGs without any computer skills. Why aren't these tools more used by teachers?

In this paper, we unravel the mystery by analyzing the needs of a group of botanists, who wish to create MLGs for a natural park. This work is part of the ReVeRIES ${ }^{1}$ project, which aims at using mobile technologies to help humans recognize the trees in a fun and motivating way. In the following section of this paper, we present a design experiment where botanist and learning game experts design MLG scenarios. We then use current authoring tools to implement these scenarios. Our conclusion is that state of the art authoring tools do not allow to express these scenarios. From then, we introduce the ReVeRIES modeling language.

1 http://www.reveries-project.fr/, visited in April 2016 


\section{What Needs for Authoring Situated Learning Games?}

\subsection{Designing Mobile Learning Games for a Natural Park}

In this section, we try to identify why the existing authoring tools do not seem to be adapted to the needs of teachers and experts who wish to design MLGs. In order to do so, we organized a creativity session with a group of botanists and learning games experts who wish to create MLGs for the visitors of the Echologia ${ }^{2}$ natural park. This creativity session, described in detail in [4], resulted the production of eight MLGs.
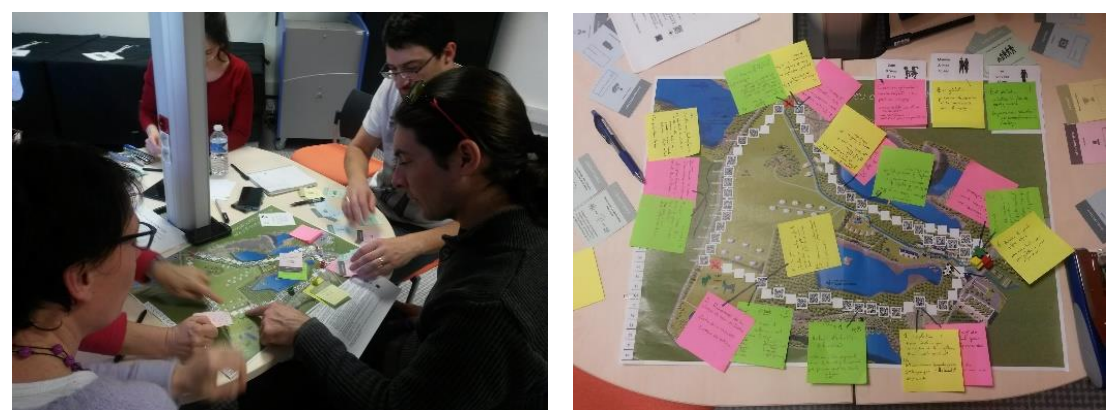

Fig. 1 Creativity session, with a map of the park, for designing MLGs

Because of the limited space of the article, we will not describe each of these scenarios, but rather their main characteristics. First of all, the designers described the MLGs as a sequence of situated game units. We deliberately chose the term "unit" because the content of each unit formed a coherent set of activities aimed at teaching the characteristics of a plant. These game units are also "situated" because they are composed of activities that can only be done in the vicinity of this real plant. As illustrated in Fig. 1, each game unit, represented by a post-it, is physically located on a map and linked to objects of interest (botanical or non-botanical) alongside the path. Most of the game units were composed of an activity that consist in finding the point of interest (i.e. the plant or a group of plants) and one or several activities that are done once they are on site. Several MLGs also integrated forms collaboration between the players of a same group.

The goal of this creativity session was to determine the types of MLGs fields experts in botany would potentially like to create for their educational outings. It is therefore important to take into consideration the fact that the Echologia park is quite particular in the fact that the visitors are forced to walk along a simple path for safety reasons. This physical limitation resulted in the fact that all the MLGs designed for the park have strictly linear scenarios. In other words, the game units are done one after the other. If the MLGs were designed for an open natural park, some of them would probably have emergent scenarios in which the game units are triggers when the players are physically in the vicinity of the point of interest. This is often the case

2 http://www.echologia.fr/, visited in April 2016 
for MLGs that offer interactive educational walks through cities or archeological sites. Another possibility is to design the scenario as an activity hub for which all the game units are available from the beginning and the players choose in witch order they want to do them. This is for example the case for Florex [5], a paper-based game used in primary school, in with the players are given exercise sheets, in relation to six specific trees in a public park.

\subsection{Limitations of Existing Authoring Tools}

After collecting eight scenarios designed during the brainstorming session, we tried to create these MLGs by using the existing authoring tools. First of all, let us note that we could only find two authoring tool specifically dedicated to MLGs: Aris and ARLearn. We therefore extended our state of the art to authoring tools designed for mobile games (FuretFactory) and for educational mobile applications (mLearn4web). In the following section, we describe the limitations we encountered with each of these tools when trying to implement the eight scenarios designed by the botanists.

Aris $^{3}$ [6] is a very rich tool but is extremely complicated to use. The main reason that makes it difficult to create game units is the fact that the model implemented by Aris is based on low level items. In other words, the user needs to create a multitude of low level items (text, quests, scenes, buttons, items for scoring and resources) and link them together with locks and triggers.

ARLearn $^{4}$ [7] is as complex to use as Aris. The authors of this tool actually recommend an "assistance phase" during which the teachers' scenarios are formalized and entered into the authoring tool by computer scientists.

FuretFactory ${ }^{5}$, on the contrary, is very easy to use. In just a few minutes, the ergonomic user interface allowed to create simple situated activities linked to a point on a map. An important limitation is the fact that the scenario is always linear (i.e. one game unit after another) and do not support collaboration between players.

We can conclude that the existing tools are either not adapted to the type of MLGs teachers want, or too complex to use. In the next section, we propose a high-level modeling language that matches the natural concepts used by teachers. We then explain the work in progress to develop a simple authoring tool, based on this modeling language, which will allow teachers to create their own MLGs.

\section{ReVeRIES Model: High-Level Modeling Language for Mobile Learning Games}

As we have seen during the analysis of the existing authoring tools, the difficulty is to create a modeling language that offers high-level concepts, similar to the natural concepts used by teachers, and that is rich enough to adapt to various types of MLGs.

http://arisgames.org/, visited in April 2016

http://portal.ou.nl/web/arlearn/, visited in April 2016

http://www.furetfactory.com/, visited in April 2016 


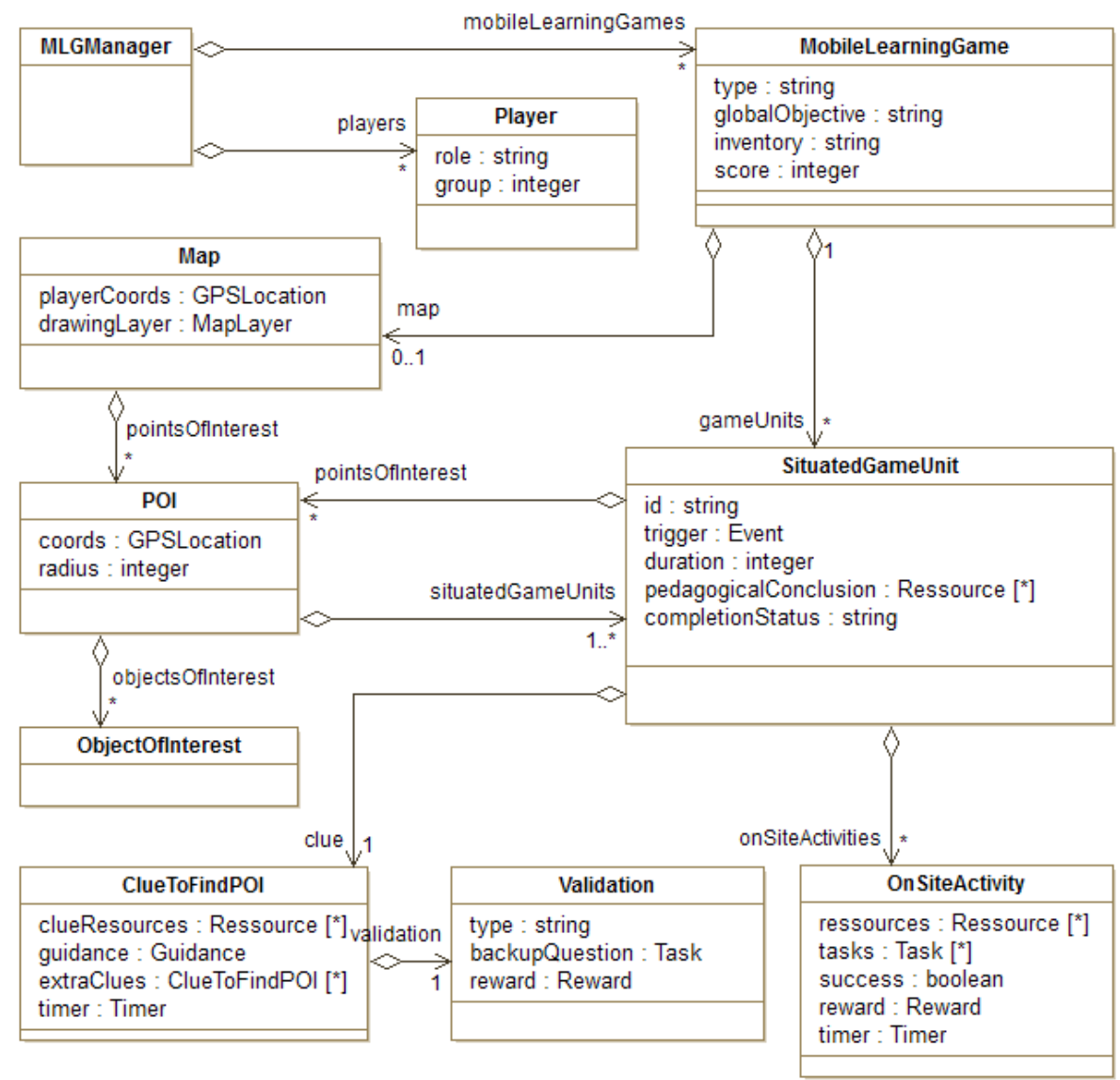

Fig. 2. ReVeRIES modeling language for Mobile Learning Games

In order to do so, we propose the ReVeRIES modeling language, partially depicted in Fig. 2. First of all, this modeling language integrates the concepts naturally used by designers during their MLG creativity session. Indeed, the central concept of the modeling language is the SituatedGameUnit that is linked to a Point Of Interest (POI) on which the game unit takes place. We can point out that this POI is a circular zone that can contain zero, one or several objects of interest (e.g. plants). The game unit is composed of:

- a trigger that starts the game unit (end of another game unit, when the player asks for it or when the learners is in proximity with a POI);

- a clue to help the player find the POI. This clue can contain resources (text, pictures and multimedia), various guidance functionalities (showing POI marker on the map or GPS, beeper or vibration guidance). The teachers can also add extra clues that can be "bought" by the players in exchange for points. It also has a form of validation to determine that the player has arrived at the POI and can therefore start the on-site activities. This validation can be done 
with GPS (the learner must be in the geographical zone of the POI), by scanning a QRcode on the POI or by using an external specific system, such as Fo$\mathrm{lia}^{6}$, to prove that the learner has found the right tree species;

- $\quad$ a reward for finding the $P O I$ (items for the inventory or points);

- zero, one or several OnSiteActivities that are meant to be done at the POI. These activities are composed of resources (text, video, augmented reality, situated chat), tasks (take a photo, collect items, compare objects, describe an object or answer a question). They also contain rewards for succeeding in the activity (item for the inventory or points);

- a pedagogical conclusion that appear when the learner signals the end of the game unit. This is the perfect place for the teacher to underline the knowledge freshly acquired by the learner.

A MobileLearningGame is composed of several SituatedGameUnits. It also has:

- a type that determines the way these game units follow each other. For a linear scenario (e.g. treasure hunt), the game units are chained up, one after the other, meaning that the end of a game unit (completion status changed to "finished"), triggers and the clue of the next unit. For an emergent scenario (e.g. interactive walk), the clue for a unit is triggers when the player is physically the vicinity of the point of interest on which the unit takes place. Finally, for an activity $\mathbf{H u b}$ (e.g. geocaching or Florex [5]), all the clues of the units are given at the beginning of the MLG and the players can therefore decide the order in which they want to do them;

- an inventory that contains all the virtual items earned as rewards (e.g. virtual objects, information sheets);

- a score that keeps track of the points earned by the player;

- a map of the geographical zone where the MLG will take place and can be viewed by the players at any time. The teacher can also choose to show the player's position and add another map layer in order to have a personalized map (e.g. map of Echologia park). The map also contains several points of interests (POIs) that can be shown or hidden depending on the time of MLG.

In order to encourage collaborative behavior, the ReVeRIES modeling language also allows teachers to send rewards, earned during the game, to the inventory of another persona of the same group.

\section{Conclusion}

In this paper, we present the ReVeRIES modeling language for creating Mobile Learning Games (MLGs). This language was designed with the help of field experts in botany, but is generic enough to be used in other fields. This language fulfills a gap in the existing MLG authoring tools that are either too complex or too specific to allow teachers to use them.

\footnotetext{
${ }^{6}$ https://itunes.apple.com/fr/app/folia/, visited in April 2016
} 
We transformed each of the classes in the ReVeRIES model into a web component. For the time being, it is possible to create instances of each class by using an html tag. For instance, one can create an OnSiteActivity by using the <on-site-activity> tag. Each of these components takes parameters defined by the user, for instance in the case of a MCQ activity, the component takes the questions, possible answers and correct answers as parameters. These parameters are then used to instantiate the components on the web page. We are currently developing an authoring tool prototype that will allow non-computer scientist to create these instances without having to manipulate html. We are now in a phase of internal testing of the prototyping tools, and we plan to test them with field specialists soon. In future work, we will focus on automating the trace generation and processing to obtain feedback on the user activity. We will also work on defining MLG patterns that could provide a basic high-level succession of activity in a learning situation.

\section{Acknowledgments}

This work is supported by the French National Agency for Research with the reference ANR-15-CE38-0004-01 (ReVeRIES project).

\section{$5 \quad$ References}

[1] C. Ardito, M. F. Costabile, A. De Angeli, and R. Lanzilotti, "Enriching Archaeological Parks with Contextual Sounds and Mobile Technology", ComputerHuman Interactions, vol. 19, no. 4, pp. 1-30, 2012.

[2] J. Huizenga, W. Admiraal, S. Akkerman, and G. ten Dam, "Mobile game-based learning in secondary education: engagement, motivation and learning in a mobile city game", Journal of Computer Assisted Learning, vol. 25, no. 4, pp. 332344, 2009.

[3] D. Spikol, "Exploring Novel Learning Practices Through Co-Designing Mobile Games", in Researching mobile learning: frameworks, tools, and research designs, Peter Lang, 2009.

[4] I. Marfisi-Schottman, P.-Y. Gicquel, and S. George, "Meta Serious Game: Supporting Creativity Sessions for Mobile Serious Games," in Proceedings of European Conference on Game Based Learning, ECGBL, Peisly, Scotland, 2016, in press.

[5] P. Marzin, E. Triquet, and B. Combaz, "Recognized trees in primary school: the game situation «Florex » : report of innovation", Concepts and misconceptions, no. 22, pp. 117-136, 2003.

[6] D. J. Gagnon, “ARIS,” Master's Thesis, University of Wisconsin-Madison, 2010.

[7] S. Ternier, R. Klemke, M. Kalz, P. Van Ulzen, and M. Specht, "ARLearn: Augmented Reality Meets Augmented Virtuality”, Journal of Universal Computer Science, vol. 18, no. 15, pp. 2143-2164, 2012. 